\title{
ATUALIZAÇÃO DE DADOS PARA O MODELO ALOK DE ALOCAÇÃO MULTIMODAL-MULTIPRODUTO. ESTUDO DE CASO: REGIÃO CENTRO-OESTE DO BRASIL
}

\section{Dissertação de Mestrado}

Dissertação apresentada como requisito parcial para obtenção do grau de Mestre pelo Programa de Pós-Graduação em Engenharia de Produção do Departamento de Engenharia Industrial da PUCRio. 


\title{
ATUALIZAÇÃO DE DADOS PARA O MODELO ALOK DE ALOCAÇÃO MULTIMODAL-MULTIPRODUTO. ESTUDO DE CASO: REGIÃO CENTRO-OESTE DO BRASIL
}

Dissertação apresentada como requisito parcial para obtenção do grau de Mestre pelo Programa de Pós-Graduação em Engenharia de Produção PUC-Rio. Aprovada pela Comissão Examinadora abaixo assinada.

\author{
Prof. José Eugênio Leal \\ Orientador \\ Departamento de Engenharia Industrial - PUC-Rio \\ Prof. Nélio Domingues Pizzolato \\ Departamento de Engenharia Industrial - PUC-Rio \\ Profa. Vânia Barcellos Gouvêa Campos \\ Departamento de Engenharia de Transporte - IME \\ Prof. José Eugênio Leal \\ Coordenador Setorial do Centro Técnico Científico - PUC-Rio
}


Todos os direitos reservados. É proibida a reprodução total ou parcial do trabalho sem autorização da universidade, do autor e do orientador.

David Leite Carrilho

Graduou-se em economia pela Faculdade de Economia Vianna Jr., chancelada pela FGV-RJ. Foi professor da Universidade Federal de Juiz de Fora (UFJF) no departamento de Análise Econômica, trabalhou como pesquisador no Projeto de Analise do Sistema Logístico e de Transportes do Corredor Centro-Oeste (ALOGTRANS). Atualmente atua como gestor de projetos no Escritório de Desenvolvimento do Centro Técnico Científico (ED.CTC) da PUC-Rio.

Ficha Catalográfica

Carrilho, David Leite

Atualização de dados para o modelo alok de alocação multimodal-multiproduto: estudo de caso: Região Centro-Oeste do Brasil / David Leite Carrilho ; orientador: José Eugênio Leal. - 2012.

121 f. : il. (color.) ; $30 \mathrm{~cm}$

Dissertação
Universidade Católica do Rio de Janeiro,

Departamento de Engenharia Industrial, 2012.

Inclui bibliografia

1. Engenharia Industrial - Teses. 2. Modelo multimodal-multiproduto. 3. Alocação de fluxo. 4. Transporte. 5. Centro-Oeste I. Leal, José Eugênio. II. Pontifícia Universidade Católica do Rio de Janeiro. Departamento de Engenharia Industrial. III. Título. 
Aos meus pais Maria Tereza e Waltencir Carrilho pelo apoio, paciência e carinho. E ao meu irmão João Daniel, por sempre acreditar que eu poderia ir além. 


\section{Agradecimentos}

Acima de tudo, agradeço a DEUS por ter dado perseverança, coragem e conforto durante toda essa minha jordana. Em especial, ao professor e orientador José Eugenio Leal pelos seus conselhos os quais foram à pedra fundamental para o meu amadurecimento como profissional, e por permitir a experiência ímpar de trabalhar no projeto ALOGTRANS, o qual foi à fonte inspiradora do presente trabalho. Agradeço a todos os professores e funcionários do Departamento de Engenharia Industrial da PUC-Rio, os quais, durante esses anos, me receberam com muito carinho e atenção.

A todas as pessoas que de certa forma, direta ou indiretamente, colaboraram para a conclusão dessa jornada. Dentre dessas pessoas, à minha família, principalmente ao meu irmão João Daniel pelo seu apoio incondicional, aos meus pais, que apesar de todas as suas limitações, sempre estiveram presentes, e em especial, in memoriam, ao meu avô Nelson, o qual sempre me apoiou com todo o seu entusiasmo.

Aos meus grandes e eternos amigos: Orivalde Soares da Silva Júnior, Denilson Lucena, Antônio Ricardo, Ana Carla, Beatriz Pancieri; os quais sempre estiveram ao meu lado em todos os momentos, apoiando-me. Agradeço à presença da minha amiga, especial, Esther Grizzendi, pelo seu carinho e companhia durante os momentos tubulosos. A presença dos professores componentes da banca, Prof. Nélio Pizzolato e a Profa. Vânia Barcellos. E agradeço, também, pela bolsa de mestrado concedida pela CAPES e ao CNPq, pela bolsa durante o trabalho desenvolvido no projeto ALOGTRANS. 


\section{Resumo}

Carrilho, David Leite; Leal, José Eugenio. Atualização de dados para o modelo ALOK de alocação multimodal-multiproduto. Estudo de caso: Região Centro-Oeste do Brasil. Rio de Janeiro, 2012. 121 p. Dissertação de Mestrado - Departamento de Engenharia Industrial, Pontifícia Universidade Católica do Rio de Janeiro.

O presente trabalho foi baseado no projeto ALOGTRANS desenvolvido pelo Departamento de Engenharia Industrial da Pontifícia Universidade Católica do Rio de Janeiro (PUC-Rio) em conjunto com outras seis instituições. Tal projeto tem como objetivo propor alternativas para mitigar e/ou eliminar os principais gargalos logísticos presentes no escoamento da safra agrícola, de forma a reduzir os custos das operações logísticas, principalmente com a operação de transporte multimodal. Para tanto, nesse projeto, irá ser feito uma análise do fluxo de produção de soja, farelo de soja, milho e açúcar da região centro-oeste brasileira, utilizando o modelo de alocação de transportes multimodal-multiproduto através da utilização do software ALOK (desenvolvido pelo departamento de engenharia industrial da PUC-Rio). Neste contexto, o trabalho desenvolvido teve como objetivo principal atualizar os dados correlacionados com os custos de transportes utilizados como parâmetros de entrada no software ALOK. Além de descrever, de forma sucinta, o atual mercado das commodities agrícolas brasileiras, bem como, as principais rotas utilizadas para o escoamento.

\section{Palavras-chave}

Modelo de alocação; Multiproduto-Multimodal; Custos com transportes. 


\section{Abstract}

Carrilho, David Leite; Leal, José Eugenio (Advisor). Data upating for the ALOK multimodal-multiproduct flow assigment model. Case study: Center-Westregion of Brazil. Rio de Janeiro, 2012. 121 p. MSc. Dissertation - Departamento de Engenharia Industrial, Pontifícia Universidade Católica do Rio de Janeiro.

The present work was based on a project called ALOGTRANS developed by Industrial Engineering Department of Catholic University of Rio de Janeiro (PUC-Rio) jointly with six institutions. The purpose of such research is to propose alternatives to mitigate and/or eliminate the main logistical bottlenecks from harvest flow in order to reduce logistical operation cost, mainly by the use of multimodal transport. In such project, we analyse the production flow of soybean, soybean meal, corn and sugar from Brazilian Midwest, using multimodal-multiproduct allocation means through ALOK software (developed by Industrial Engineering Department of PUC-Rio). In this sense, the main objective of this work is to update transportation cost related data used as input to ALOK. Furthermore, we succinctly describe the present market of Brazilian commodities and also the main flow routes.

\section{Keywords}

Allocation of model; Multiproduct-Multimodal; Cost of transportations 


\section{Sumário}

1. Introdução

2. Panorama da produção e do transporte das principais commodities agrícolas destinadas à exportação 19

2.1. Soja é farelo de soja 19

2.1.1 Produção de soja no Brasil 19

2.1.2. Destino da produção de soja 22

2.1.3. Exportação da soja e farelo de soja e seus principais corredores de escoamento $\quad 24$

2.1.3.1. Exportação da soja e farelo de soja 24

2.1.3.2 Principais portos e corredores usados para exportação 27

2.2. Milho 30

2.2.1. Produção de milho no Brasil 30

2.2.2. Destino da produção de milho 33

2.2.3. Exportação do milho e seus principais corredores de escoamento 34

2.2.3.1. Exportação do milho 34

2.2.3.2. Principais portos e corredores usados para exportação 36

2.3. Açúcar 38

2.3.1 Produção de açúcar no Brasil 38

2.3.2. Destino de produção do açúcar 40

2.3.3. Exportação do açúcar e seus principais corredores de escoamento 42

2.3.3.1. Exportação de Açúcar 42

2.2.3.2. Principais portos e corredores usados para exportação 43

3. O transporte no Brasil 47

3.1. Panorama do Transporte nacional de cargas 47 
3.3. A multimodalidade no Brasil 52

4. Planejamento de transportes de cargas

4.1. Introdução aos sistemas de transportes 55

4.2. Modelos de Planejamento de Cargas 57

4.2.1. Síntese dos modelos 58

4.3. STAN/ALOK - Modelo multimodal-multiproduto de transporte de carga 61

4.3.1. Representação da rede 61

4.3.2. Formulação do modelo multimodal-multiproduto (ótimo do sistema) 65

4.3.3. Ótimo do sistema 68

4.3.4. Algoritmo de Soluções 70

5. Estudo de caso: Região Centro-Oeste (CO) 73

5.1. Corredor agrícola Centro-Oeste e os modos de transportes utilizados 73

5.2. Atualização dos custos de transportes para alocação de fluxos multiproduto em uma rede multimodal - ALOK 77

5.2.1 Modelagem dos custos ferroviários no ALOK 78

5.2.1.1 Formulação matemática 78

5.2.1.2. Custo operacional 79

5.2.1.3. Custo do tempo nos links 80

5.2.1.4. Custo de consumo de combustível 83

5.2.2. Modelagem dos custos rodoviários no ALOK 84

5.2.2.1. Conceitos de custos rodoviários 84

5.2.2.2. Função dos custos rodoviário 86

5.2.3. Atualização do custo operacional ferroviário 89

5.2.3.1. Atualização do custo operacional rodoviário 91

5.3. Aplicação da atualização dos parâmetros no ALOK 101 
6. Considerações finais 102

$\begin{array}{ll}\text { 7. Referencial bibliográfico } & 105\end{array}$

ANEXO A: Aplicação dos parâmetros atualizados no ALOK 112 


\section{Lista de tabelas}

Tabela 1 - Volume de milho exportado por porto brasileiro 36

Tabela 2 - Matriz de Transporte de carga e o custo no Brasil 48

Tabela 3 - Conceitos sobre intermodalidade e multimodalidade 52

Tabela 4 - Síntese dos principais modelos de transporte de cargas 59

Tabela 5 - Características quantitativas da rodovia 85

Tabela 6 - Estado de conservação da rodovia / Índice QI 85

Tabela 7 - Custos por tipo de veículos 86

Tabela 8 - Custo Operacional ferroviário em reais (Material Rodante) 90

Tabela 9 - Custo Operacional ferroviário $(\mathrm{R} \$ / \mathrm{km}) \quad 91$

Tabela 10 - Estimativa do Custo Operacional rodoviário 96

Tabela 11 - Fator de atualização do Custo Operacional rodoviário em Crz\$/km (GEIPOT) 97

Tabela 12 - Fator de atualização do Custo Operacional rodoviário 98

Tabela 13 - Custo Operacional atualizados com o fator de atualização

Tabela 14 - Velocidade e índice de desempenho no consumo de combustível em via pavimentada

Tabela 15 - Velocidade e índice de desempenho no consumo de combustível em via não pavimentada (atualizada)

Tabela 16 - Velocidade e índice de desempenho no consumo de combustível em via pavimentada

Tabela 17 - Velocidade e índice de desempenho no consumo de combustível em via não pavimentada (atualizada)

Tabela 18 - Funções de custos no ALOK 


\section{Lista de Gráficos}

Gráfico 1 - Evolução da área plantada da soja no Brasil 20

Gráfico 2 - Participação dos Estados na exportação de soja em grãos

Gráfico 3 - Volume exportado de soja em grãos 25

Gráfico 4 - Volume exportado de farelo de soja 26

Gráfico 5 - Soja em grãos e farelo exportado por porto brasileiro 27

Gráfico 6 - Evolução da produção, produtividade e área plantada do milho

Gráfico 7 - Evolução das exportações brasileira de milho 35

Gráfico 8 - Participação dos Estados na exportação de milho (2010) 36

Gráfico 9 - Principais Estados produtores de açúcar 43

Gráfico 10 - Principais portos de exportadores de açúcar 44

Gráfico 11 - Matriz de transporte de cargas no Brasil 48

Gráfico 12 - Comparação dos investimentos (PAC x PNLT) 50

Gráfico 13 - Evolução dos OTM's no Brasil (2005 a 2009) 53

Gráfico 14 - Relação entre o custo e a capacidade de um arco 65 


\section{Lista de Figuras}

Figura 1 - Principais regiões produtoras de soja no Brasil 21

Figura 2 - Principais destinos da produção da soja no Brasil 23

Figura 3 - Principais regiões produtoras de milho no Brasil 32

Figura 4 - Principais destinos da produção de milho no Brasil 33

Figura 5 - Principais Estados produtores de açúcar 39

Figura 6 - Principais destinos da produção de açúcar 41

Figura 7 - Número de matrizes de OTM’s no Brasil por Estado 54

Figura 8 - Relação básica do sistema de transporte 56

Figura 9 - Rede física (primeira proposta) 62

Figura 10 - Rede física (segunda proposta) 63

Figura 11 - Rede física (terçeira proposta) 64

Figura 12 - Algoritmo do modelo de alocação multimodalmultiproduto $\quad 71$

Figura 13 - Rodovia BR-364 e sua abrangência 74

Figura 14 - Rodovia BR-163 e BR-277 74

Figura 15 - Mapa ferroviário 75

$\begin{array}{ll}\text { Figura } 16 \text { - Bacia do Tietê-Paraná } & 76\end{array}$ 

desígnios serão estabelecidos (Pv. 16:3). 